\title{
Evolution of Grain Structure in Thin Film Reactions*
}

K. BARMAK, J.M. RICKMAN, and C. MICHAELSEN ${ }^{\dagger}$

Department of Materials Science and Engineering, Lehigh University, 5 East Packer Avenue, Bethlehem, PA 18015

$\dagger$ Institute for Materials Research, GKSS Research Center, D-21502

Geesthacht, Germany

Due to miscommunication, this updated Fig. 2a was not included in our article.

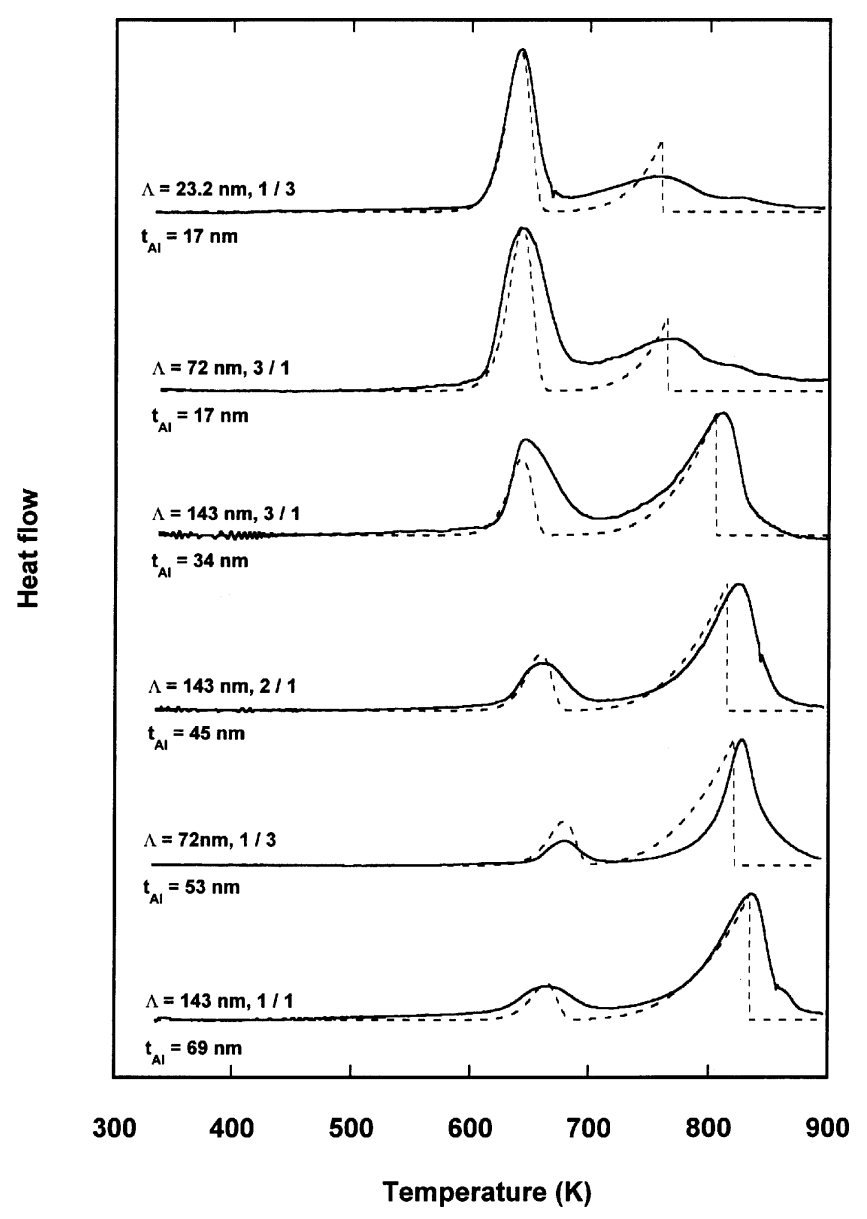

*Journal of Electronic Materials, Vol. 26, No. 9, pp. 1009-1020 (1997). 